固 

Satoe Horii .

Die gesetzlichen Umgehungen im islamischen Recht (hiyal) 
ISLAMKUNDLICHE UNTERSUCHUNGEN • BAND 239

\author{
begründet \\ von \\ Klaus Schwarz \\ herausgegeben \\ von \\ Gerd Winkelhane
}


ISLAMKUNDLICHE UNTERSUCHUNGEN • BAND 239

\section{Satoe Horii}

\section{Die gesetzlichen Umgehungen im islamischen Recht (ḥiyal)}

Unter besonderer Berücksichtigung der Ğannat al-aḥkām wa-ğunnat al-ḩussām des Ḥanafiten $\mathrm{Sa}^{C} \mathrm{i} i \mathrm{~d} b$.

'Alī as-Samarqandī (gest. 12. Jhdt.) 
Die Deutsche Bibliothek - CIP-Einheitsaufnahme

\author{
Horil, Satoe: \\ Die gesetzlichen Umgehungen im islamischen Recht (hiyal) : Unter besonderer \\ Berücksichtigung der Gannat al-aḥkām wa-ğunnat al-ḩușșām des Hanafiten Sa9̄d b. \\ cAli as-Samarqandi (gest. 12. Jhdt.) / Satoe Horii. - Berlin : Schwarz, 2001 \\ (Islamkundliche Untersuchungen ; Bd. 239) \\ Zugl.: Köln, Univ., Diss., 2000 \\ ISBN 3-87997-292-3
}

Alle Rechte vorbehalten.

Ohne ausdrückliche Genehmigung des Verlages

ist es nicht gestattet, das Werk oder einzelne Teile daraus

nachzudrucken oder zu vervielfältigen.

(c) Gerd Winkelhane, Berlin 2001.

Klaus Schwarz Verlag GmbH, Postfach 4102 40, D-12112 Berlin

ISBN 3-87997-292-3

Druck: Offsetdruckerei Gerhard Weinert GmbH, D-12099 Berlin

ISSN 0939-1940

ISBN 3-87997-292-3 